2. Bloom SW. Structure and ideology in medical education: an analysis of resistance to change. J Health Soc Behav. 1988;29(4):294-306.

3. Bloom SW. The medical school as a social organization: the sources of resistance to change. Med Educ. 1989;23(3):228-241.

4. Christakis NA. The similarity and frequency of proposals to reform US medical education. Constant concerns. JAMA. 1995;274(9):706-711.

5. Whitehead CR, Hodges BD, Austin Z. Captive on a carousel: discourses of "new" in medical education 1910-2010. Adv Health Sci Educ Theory Pract. 2013;18(4):755-768.

6. Ebell MH. Future salary and US residency fill rate revisited. JAMA. 2008;300(10):1131-1132.

7. Frenk J, Chen L, Bhutta ZA, et al. Health professionals for a new century: transforming education to strengthen health systems in an interdependent world. Lancet. 2010;376(9756):1923-1958.

8. American Medical Association (AMA). Accelerating change in medical education. 2012. http://www.ama-assn.org/ama/pub/about-ama/ strategic-focus/accelerating-change-in-medical-education.page.

9. Funkenstein DH. Some myths about medical school admissions. J Med Educ. 1955;30(2):81-88.

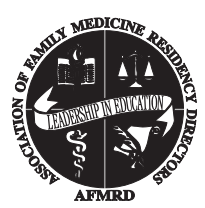

From the Association of Family Medicine Residency Directors

Ann Fam Med 2013;582. doi:10.1370/afm.1589.

\section{FM-RC REQUIREMENTS - LESS IS MORE}

The ACGME Review Committee of Family Medicine (RC-FM) released its revision of the core requirements earlier this year for the first time since 2007. The proposed requirements, at 31 pages, are $20 \%$ shorter than the earlier requirements. The new requirements, rather than detailing the specifics needed for each and every aspect of family medicine education, direct programs as to what is most important, they provide the "spirit of the law," but have eliminated much of the "letter." For example, the old $\mathrm{RC}$ requirements for a family medicine center (FMC) were 3 pages long; the new guidelines for a family medicine practice (FMP) are one page, and much more general than specific.

There are 2 important benefits to the above changes, and 2 notes of caution. The first benefit is the new requirements addresses the reductionist view of human health as the sum of the individual parts that developed in our requirements. Family medicine as a specialty specializes in people ; it is the only specialty not limited by age, gender, or organ system. To define the knowledge needed by family physicians as a litany of systems of the human body undermines the quintessential nature of our specialty.

The second important benefit of the proposed changes is that they allow for more autonomy of pro- grams to address how to best teach family medicine. As a specialty, we struggle to balance the common essence of what it means to be a family physician with different geographical needs. The proposed requirements give an overview of what is needed, without descending into a laundry list of specifics. It allows the program director to modify the curriculum of the program to best meet the clinical and educational needs of his or her own program, and of the community they serve.

The notes of caution relate to how we as program directors interact with new requirements. First, the $\mathrm{RC}$-FM is to be commended for reducing our new proposed program requirements from 39 to 31 pages. One of the contributing factors for the requirements being so long in the first place was the interaction between program directors asking for clarification on citations, and a well-intentioned review committee providing it - and we slowly increased the length and specificity of our program requirements. The specifics become a double-edged sword-greater clarity in requirements means greater detail, which means longer and more cumbersome requirements that can stifle innovation and creativity, and interfere with a program flexing to meet the needs of its community.

The second caution is a need to shift our source for justification of institutional resources away from the pared down $\mathrm{RC}$ requirements, and towards the readily updatable RC family Medicine FAQ document. This will allow programs to still utilize the ACGME as an official backstop without bloating the requirements again.

AFMRD is well positioned as an organization to help our members meet the challenges and seize the opportunities of these changes. Two recent initiatives undertaken by AFMRD to help family medicine programs be the best they can be: The Family Medicine Residency Curriculum Resource (RCR) and the Residency Performance Index (RPI). The RCR will allow curriculum to be shared among programs nationwide. The Residency Performance Index (RPI) allows programs to self-assess, compare themselves to their peers, and develop improvement strategies. We also recognize there is much work to be done in the areas of innovation support and measurement and communication. There are many programs of excellence among us, trying many innovations, led by directors of excellence and creativity, and the more AFMRD can support all of them, allow them to exchange ideas and learn from each other, the better off we will all be.

Stephen Scbultz, MD, Natasba Bbuyan, $M D_{i}$

Brian Crownover, $M D_{i}$ Grant Hoekzema, $M D_{i}$

Lisa Maxwell, MDi Michael Mazzone, $M D_{i}$

W. Fred Miser, $M D_{i}$ Karen Mitchell, MDi

Todd Shaffer, MD, MBA, Michael Tuggy, MD 